\title{
Estresse em árbitros de Ginástica Rítmica
}

https://doi.org/10.11606/issn.1981-4690.V35i2p283-292

Paula Barreiros Debien*
Maurício Gattás Bara*
Cleiton Pereira Reis*
Varley Teoldo da Costa
*Universidade Federal

de Juiz de Fora, Juiz de

Fora, MG, Brasil.

**Universidade Federal

de Minas Gerais, Belo Horizonte, MG, Brasil.

\section{Resumo}

0 objetivo do estudo foi identificar e classificar o estresse em árbitros brasileiros de ginástica rítmica (GR). Foram entrevistados 10 árbitros brasileiros de GR de nível internacional, com média de idade de $37.6 \pm$ 6.6 anos. Realizou-se a transcrição das entrevistas e, posteriormente, uma análise qualitativa foi feita, por meio de miniunidades (MUs). Estas MUs foram classificadas em três categorias: estresse social, biológico e psicológico. Além da dificuldade de conciliar a vida social e a atividade profissional, o relacionamento com outros árbitros, comissão técnica e espectadores são fontes importantes de estresse social para os entrevistados. Quanto ao estresse biológico, os árbitros se queixaram da longa duração das competições. Eles frequentemente apresentam algum tipo de desconforto físico durante a atuação laboral. 0 estresse psicológico que estes profissionais estão submetidos tem relação com o desgaste em atribuir notas à atuação das atletas, além do nível das competições que os árbitros atuam e da necessidade de interpretar o código de pontuação. Conclui-se que diferentes fatores envolvidos na atividade laboral dos árbitros brasileiros de GR se interagem e se relacionam no aparecimento do estresse nestes profissionais.

Palavras-Chave: Atividade laboral; Educação Física e Treinamento; Esportes; Pesquisa qualitativa.

\section{Introdução}

Os árbitros exercem um importante papel no meio esportivo, já que suas açóes podem afetar diretamente o andamento de uma competição, mesmo involuntariamente ${ }^{1,2}$. $\mathrm{O}$ árbitro tem a autoridade para fazer cumprir as regras de uma modalidade esportiva, e as decisóes tomadas por este profissional são consideradas definitivas e soberanas ${ }^{2}$. Estudos vêm mostrando que árbitros são susceptíveis a várias fontes de estresse, sendo que este contexto pode influenciar negativamente a atividade laboral destes indivíduos ${ }^{1,3-5}$.

O estresse refere-se a uma desestabilização psicofísica ou uma perturbação do equilíbrio na relação pessoa-meio ambiente ${ }^{6}$. Em geral, o estresse é resultado da interação do homem com seu meio ambiente físico e sociocultural e pode ser compreendido como produto da tridimensionalidade entre os sistemas social, biológico e psicológico ${ }^{6-8}$. Na perspectiva biológica, o estresse está relacionado às reaçôes orgânicas provocadas por estímulos desestabilizadores do equilíbrio homeostático. No que tange ao sistema social, são compreendidas as relaçóes socioculturais do homem com o seu mundo e de que forma os grupos se organizam ${ }^{6}$. Em relação aos aspectos psicológicos, o estímulo estressor é mediado por um processo subjetivo de avaliaçáa do mesmo (prospectiva ou retrospectiva), que media as consequências oriundas do estresse (positivas ou negativas) $^{6,7}$.

Essa variável que vem sendo estudada na atividade laboral dos árbitros esportivos ${ }^{2,3,5,9}$, tendo em vista que esses profissionais podem ter o seu rendimento prejudicado pelas situaçóes estressantes que vivenciam antes, durante e após a realização das competições ${ }^{6,10}$. Os árbitros estáo submetidos a diferentes fontes de estresse, tais como cometer erros e lidar com abuso verbal de atletas, treinadores e espectadores ${ }^{2,11,12}$. Tal contexto, além de prejudicar a qualidade das decisóes dos árbitros e resultados de competiçóes, pode fazer com que estes profissionais abandonem a arbitragem esportiva ${ }^{4,13}$. 
O foco das investigaçóes sobre estresse na arbitragem está relacionado à identificação das causas que geram este problema. Os estudos têm investigado os fatores estressantes em árbitros de esportes coletivos como no basquetebol e voleibol ${ }^{10}$, futebol ${ }^{1,10,14}$, handebol ${ }^{10,15}$, e hóquei sobre o gelo ${ }^{16}$.

Modalidades individuais, como a ginástica rítmica (GR), têm recebido menor atenção em relaçáo à identificação dos fatores estressantes na arbitragem $^{3}$. Apesar deste problema já ter sido reportado por DUdA, Borysowicz e ST Germaine ${ }^{17}$ na ginástica artística, observa-se uma escassez de trabalhos científicos na área do estresse em árbitros de ginástica, em especial na GR, como mostra uma revisão sistemática sobre o tema ${ }^{3}$. PerederiJ ${ }^{18}$, por sua vez, investigou os fatores objetivos e subjetivos que influenciam negativamente a atuação dos árbitros de GR, mas não identificou, de forma específica, as fontes de estresse laborais que afetam estes profissionais.

A subjetividade inerente ao processo de avaliação do desempenho das atletas desta modalidade é um fator que influencia diretamente o trabalho dos árbitros de $\mathrm{GR}^{19,20}$. Nesta modalidade não existe

\section{Método}

Uma abordagem qualitativa foi utilizada para a realização do presente estudo ${ }^{24-26}$. Através deste tipo de pesquisa é possível ter uma visão holística acerca de um fenômeno. Para Mazzola, Schonfeld e SPECTOR $^{8}$, pesquisas qualitativas podem desempenhar um importante papel na descoberta de fatores estressantes que não estavam originalmente previstos por pesquisadores que utilizam instrumentos estruturados em investigaçóes quantitativas. Ao se utilizar uma abordagem qualitativa é possível uma maior compreensão das vivências dos participantes dentro do contexto nos quais eles estão inseridos ${ }^{24-26}$.

\section{Amostra}

A amostra foi composta por dez árbitros brasileiros de GR (um do sexo masculino e nove do sexo feminino) com idade média de $37.6 \pm 6.6$ anos e tempo médio de arbitragem de $16.0 \pm 4.9$ anos. Os participantes deste estudo correspondem a, aproximadamente, $29 \%$ da população dos árbitros internacionais que integraram o quadro da Confederação Brasileira de Ginástica (CBG) um sistema automático de avaliação, de modo que a função do árbitro é, primordialmente, a de avaliador do desempenho da atleta, aumentando ainda mais a responsabilidade do árbitro nas suas decisôes ${ }^{3,21-23}$. Árbitros de GR que atuam em competiçóes internacionais podem estar sujeitos frequentemente a fontes de estresse, devido à importância dos campeonatos e as pressões sofridas oriundas de treinadores, imprensa, espectadores.

O mapeamento específico das fontes de estresse em árbitros de GR poderá contribuir para se otimizar o ambiente laboral destes profissionais, bem como auxiliar no desenvolvimento de ferramentas psicométricas de avaliação do estresse. Porém, para que estas açôes sejam possíveis, é importante identificar, nesta modalidade esportiva, os fatores que contribuem para a manifestação do estresse e, também, classificá-los de acordo com as especificidades deste constructo e do contexto esportivo em questáo ${ }^{8}$. Assim, os processos de diagnóstico e intervenção a parir destas variáveis poderão ser otimizados. Dessa forma, o objetivo do estudo é identificar e classificar o estresse em árbitros brasileiros de GR. no ciclo 2009-2012.

Os critérios de inclusão foram: ser árbitro de nível internacional no ciclo olímpico 2009-2012, ser integrante do quadro de árbitros da CBG e ter atuado em campeonatos nacionais e/ou internacionais no referido ciclo olímpico. $\mathrm{Na}$ apresentação e discussão dos resultados, os árbitros tiveram suas identidades preservadas, sendo aleatoriamente identificados (ex.: A1, árbitro 1).

\section{Instrumentos}

Foi utilizado um roteiro de entrevista semiestruturada ${ }^{27-28}$, elaborado para avaliar o estresse em árbitros de GR. As entrevistas poderiam se desviar do curso inicial, dependendo da necessidade. A ordem das perguntas pode ser flexível, pois o investigador estabelece a sequência das mesmas de acordo com o andamento da entrevista ${ }^{25,29}$.

O roteiro de entrevista foi desenvolvido com base na concepçáo do estresse enquanto produto tridimensional da inter-relação pessoa-meio ambiente ${ }^{6,8}$, sendo que a 
variável estresse pode ser compreendida em estresse social, biológico e psicológico 7 . A validação do conteúdo das entrevistas passou pela aprovaçáo de três experts, doutores em psicologia do esporte e que conduzem estudos na área do estresse, através da técnica de expert rating ${ }^{29}$. A concordância entre os peritos foi levada em consideração na análise dos dados.

\section{Procedimentos}

Este estudo foi aprovado pelo Comitê de Ética em Pesquisa da Universidade Federal de Minas Gerais (CAAE 02532712.8.0000.5149). Inicialmente, foi realizado um contato com a CBG em busca de anuência da instituiçấo para realização do estudo. Em seguida, os árbitros foram contatados via correio eletrônico, para esclarecimentos e convidando-os a participar do estudo. Mediante resposta positiva, as entrevistas foram agendadas de acordo com a convocaçáo destes árbitros para as competiçóes oficiais da CBG no decorrer do ano de 2012. Nas datas agendadas, cada voluntário assinou o Termo de Consentimento Livre e Esclarecido. Todas as entrevistas foram feitas pela mesma pesquisadora,

\section{Resultados}

A FIGURA 1 mostra a classificação das MU's em categorias e subcategorias. A seguir os resultados seráo descritos e interpretados de acordo com as dimensôes: estresse social, biológico e psicológico.

\section{Estresse Social}

Esta categoria apresentou maior número de MU's neste estudo (FIGURA 1). Pode-se observar que as relaçóes sociais são uma grande fonte de estresse para os árbitros estudados. Através do relato destes profissionais, observou-se que uma das causas do surgimento do estresse social é o relacionamento com os outros árbitros. Os árbitros de GR atuam em conjunto e, muitas vezes, é necessário diálogo para que haja consenso na nota. Além disso, existem árbitros superiores que são responsáveis por supervisionar o julgamento e desempenho dos demais, bem como controlar o andamento da competição como um todo. Este relacionamento entre pares pode envolver confrontos e abusos expert em GR, realizadas de forma individual, em local privativo e tiveram duração média de 40 minutos.

\section{Análise de dados}

A análise dos dados foi feita seguindo os passos de transcrição, organizaçâo e interpretaçãa ${ }^{25,29}$. Os dados foram transcritos em letra Arial, tamanho 12, com espaçamento 1,5 entre as linhas, produzindo um total de 103 páginas. As transcriçōes das entrevistas foram enviadas aos árbitros para a confirmação da veracidade dos dados.

As narrativas foram analisadas por meio de miniunidades (MU's). Uma MU representa uma parte, que pode ser uma linha, parágrafo ou mais de um parágrafo do corpo de um texto, que exemplifica uma ideia expressada pelo entrevistado de forma clara e objetiva ${ }^{24}$. As MU's passaram por um processo de análise por parte dos investigadores, com o objetivo de destacar as mais pertinentes para este estudo. Em seguida, os dados foram encaminhados para três experts, doutores em psicologia do esporte e que conduzem estudos na área do estresse, que categorizaram e subcategorizaram as MU's dentro da concepção de tridimensionalidade.

devido às discordâncias e até mesmo pela existência de atuação tendenciosa de algum árbitro dentro da equipe (banca) de arbitragem. As divergências na percepção subjetiva de avaliação dos exercícios também foram relatadas como estressantes, pois os pensamentos diferentes geram atritos dentro da banca de arbitragem, assim como as mudanças de nota, quando são necessárias (solicitada pelos árbitros superiores), devido a algum erro cometido ou critério divergente. A MU a seguir ilustra este tipo de estresse:

\footnotetext{
"Porque muitas vezes outros árbitros não concordam em modificar suas notas quando você solicita, e isso causa certo desconforto na arbitragem, porque, pelo menos no meu caso, eu não gosto de ficar pedindo para outra pessoa fazer uma coisa que ela náo concorda em fazer (...), entáo essas mudanças de nota me causam sim um estresse durante a competição.” A2.
}

O relacionamento com os treinadores e com as comissões técnicas foi relatado como fator de 
FIGURA 1 - Classificação das Miniunidades relacionadas ao estresse em árbitros brasileiros de GR.

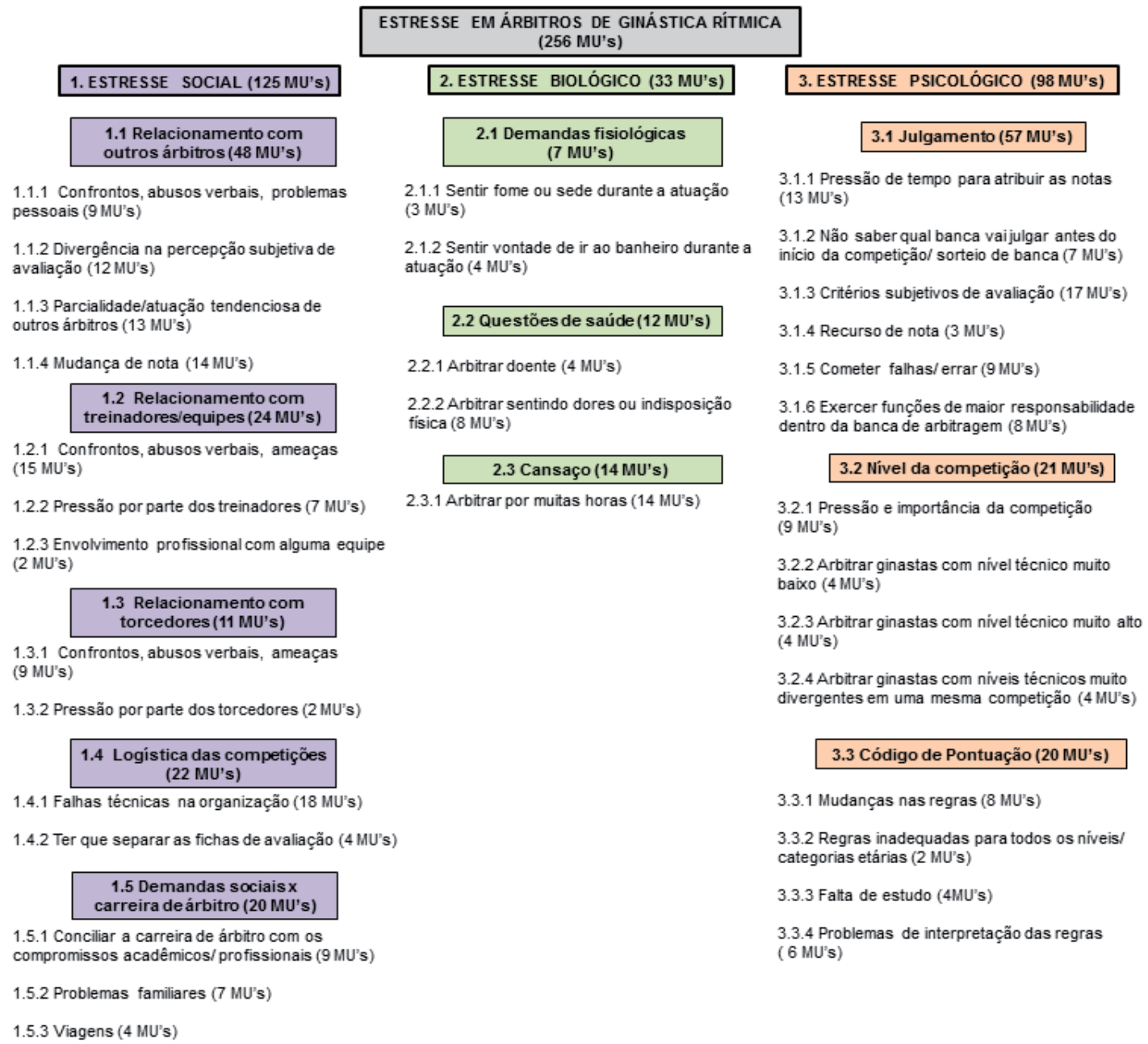

estresse pelos árbitros, sobretudo, pela discordância em relação às notas. Em competiçóes oficiais as notas são divulgadas em painéis (visíveis a todos) logo após a apresentação de cada ginasta. Após a divulgação, os treinadores têm o direito à revisão por vídeo das notas de dificuldade (recurso), por meio de requerimento formal e pagamento de taxa. Entretanto, abordagens informais são comuns, e esse tipo de pressão sofrida pelos árbitros, bem como ameaças e agressóes por parte dos treinadores, geram estresse.

\footnotetext{
"Se o técnico chega agressivamente, o árbitro tem todo o direito de não responder, e isso gera um grande estresse, tanto para o técnico quanto para o árbitro. (...). A agressão gera agressão, e gera estresse. Então, eu acho que de todas as partes têm que conversar de uma forma
}

\begin{abstract}
tranquila, mesmo quando todas as partes estando com os ânimos alterados (...).” A10.
\end{abstract}

Para os árbitros de GR, o relacionamento com os espectadores dos eventos que atuam se mostrou como mais um fator de estresse social. Mesmo que nesta modalidade as manifestaçóes da torcida tenham características mais amenas que das modalidades coletivas, as ofensas e pressões exercidas pelos espectadores quanto à insatisfação como as notas também estressam os árbitros de GR, como pode ser percebido nesta MU:

\footnotetext{
"Quando a torcida abusa, tem um comportamento inadequado, estressa muito, nossa (...) tem muito juiz que sai chorando, eu já chorei, porque falou coisa da minha família. Este tipo de coisa não dá para segurar, é
} 
bem constrangedor para a gente." A7.

Em geral, a banca de arbitragem é posicionada à frente do tapete de competição, preferencialmente, em um nível mais alto (palco). Porém, dependendo da estrutura do local, a banca pode ficar bem próxima às arquibancadas ou da aparelhagem de som, ou mal posicionada em relação ao tapete. Foi observado que qualquer falha técnica como o som muito alto, má posição da mesa de arbitragem para visualização completa e nítida da série, assim como uma programação equivocada, podem gerar estresse nestes profissionais. Abaixo um relato ilustrativo de falhas na organização enquanto fator de estresse para os árbitros de GR:

\begin{abstract}
"A organizaçáo, isso me estressa, principalmente quando o som está alto e muito próximo da arbitragem. A questão do tapete ser muito próximo chega a estressar, a gente também não consegue arbitrar corretamente (...). Agora a questão de atraso, é devido à organização mesmo. Isso estressa muito. Imagina uma falha dessa numa competiçáo internacional. Quando o som não funciona também, complica muito a competiçâa. Isso acaba ficando estressante para o árbitro. ” A6.
\end{abstract}

Anualmente, os árbitros enviam à CBG suas disponibilidades para atuarem em determinados eventos previstos no calendário da entidade. Entretanto, as dificuldades de conciliar a carreira de árbitro de GR com a vida pessoal e compromissos acadêmicos e/ou profissionais foram abordadas como fatores de estresse pelos entrevistados. Ademais, eles afirmam que as viagens para arbitrar podem ser estressantes pela duraçáo e condiçóes, além de nem sempre conseguirem ser liberados com facilidade de seus compromissos para poderem atuar na arbitragem. Abaixo um exemplo deste fator de estresse:

"Eu tento conciliar os trabalhos, porque, na verdade, aqui eu estou trabalhando, mas eu não deixo de estar à disposição do meu emprego lá na minha cidade. Então, isso me estressa pois eu tenho que estar, realmente, cumprindo as duas agendas (...)" A1.

\section{Estresse biológico}

Como mostra a FIGURA 1, o estresse biológico foi a categoria que menos gerou MU's neste estudo. Os árbitros de GR afirmaram que o surgimento deste estresse está ligado às diferentes demandas fisiológicas que estes profissionais passam enquanto estão atuando.
Por vezes, os árbitros sentem fome, sede e vontade de ir ao banheiro enquanto estão arbitrando, mas estão sujeitos ao cumprimento da programaçáo do evento, o que lhes causa estresse, conforme relatado abaixo pelo árbitro A2:

"Principalmente quando está com vontade de ir ao banheiro,
isso estressa, se você fica agoniada esperando a hora do
intervalo e dá um estresse absurdo. Não dá para sair no meio
da competição para ir ao banheiro, isso é complicado" A2.

Os entrevistados relataram que se, por ventura, eles estão com alguma indisposição ou dor enquanto estão arbitrando, isso se constitui um fator de estresse biológico, pois gera desconforto e desconcentração. Alguns relataram que, muitas vezes, este desconforto é consequência de outros fatores de estresse. Na MU abaixo, o árbitro A9 fala sobre o estresse biológico causado pelas dores e indisposiçóes:

“(...) já tive muita dor de cabeça em competição. Meu Deus! Chegou a me dar ânsia de vômito, eu tomava remédio, não passava. (...). E isso aí é realmente o que me perturba, porque eu não consigo raciocinar direito, você fica meio fora do ar. É necessário continuar na competição arbitrando" A9.

Ainda nesta dimensão, as competições com longa duração foram relatadas pelos árbitros como cansativas e, consequentemente, causadores de estresse. Em sua maioria, os árbitros disseram que o cansaço influencia de forma negativa no seu desempenho. A MU abaixo mostra isso:

\footnotetext{
“(...) se é um campeonato muito longo, quando você já está no último dia de competição a tendência é você estar mais cansado. Isso acaba afetando de alguma forma o critério que você está avaliando. Eu acho que talvez seja nesse momento que algumas notas não batam, porque aí começa realmente a cansar um pouco mais e estressar. ” A3.
}

\section{Estresse Psicológico}

O estresse psicólogo está relacionado ao julgamento das notas que serão atribuídas às apresentaçóes das atletas, ao nível das competiçóes que os árbitros atuam e à interpretação do código de pontuação por parte destes profissionais.

Em relaçáo ao julgamento das notas, os árbitros de GR relataram que diversos podem ser os fatores que lhes causam estresse. $O$ fato de não saber, momentos antes de atuar, qual banca vai julgar, ou até mesmo o fato de exercer determinada função de maior 
responsabilidade dentro da banca de arbitragem são tidos como estressantes para estes árbitros (as funçōes são sorteadas antes da competição se iniciar). A origem do estresse psicológico também está ligada a momentos quando estes profissionais sentem que cometeram algum erro em seu julgamento. Além destes, fatores específicos foram relatados pelos árbitros como os critérios subjetivos de avaliação e o pouco tempo para se atribuir uma nota após o término do exercício da ginasta. A MU abaixo ilustra este tipo de estresse:

"A Ginástica Rítmica é um esporte que por si só nos estressa, porque ainda que com toda sua objetividade, o árbitro lida com a subjetividade humana, tudo é muito subjetivo, até os critérios para se avaliar as dificuldades." A1.

O nível técnico e importância das competiçôes em que estão atuando também foram levantados como fatores de estresse para os árbitros de GR. Atuar em eventos importantes, como seletivas, causa estresse nos árbitros, pois eles se sentem sob muita pressão devido à grande responsabilidade de escolher as melhores ginastas para representarem o país em eventos internacionais, por exemplo.

\begin{abstract}
“(...) quando você vai para um evento, é uma responsabilidade. Você tem que mandar as melhores meninas para um evento internacional, elas estão representando o nosso país. (...). Você chegar com esse estresse, já pensando que vai ser difícil. Aí sim, eu tendo a ficar estressada e nervosa." A6.
\end{abstract}

As regras de avaliação e julgamento da GR estão presentes no código de pontuação específico da modalidade, elaborado e revisado a cada ciclo olímpico pelo comitê técnico de GR da Federação Internacional de Ginástica (FIG). Essas revisôes e alteraçóes podem ocorrer em menor espaço de tempo, em um mesmo ciclo, dependendo das percepçóes deste comitê sobre os resultados das competiçôes internacionais. Diante disso, o código de pontuaçáo foi apontado como um fator de estresse em função das mudanças frequentes que acontecem nas regras. Além de mudarem com frequência, grande parte das regras da GR possui elevado grau de subjetividade (principalmente quanto aos aspectos artísticos), o que leva a diferentes interpretaçōes por parte de árbitros e treinadores.

Outro problema, de acordo com os árbitros, refere-se ao fato de que o código de pontuação não é adequado e não possui adaptaçóes às categorias iniciais e/ou às ginastas de nível técnico inferior, fato que atrapalha o árbitro nas suas decisóes. Por fim, os próprios árbitros disseram que a falta de tempo para estudar as regras e suas alteraçōes geram estresse durante a atuação, pois isto prejudica a qualidade dos resultados das competiçóes e à modalidade como um todo. Abaixo um exemplo de MU relacionada às mudanças constantes nas regras:

\footnotetext{
"O que me estressa é essa mudança constante de regra. Quando tu está ali, quando domina aquele assunto, aí tu tens que voltar a estudar tudo de novo (...) e isso me estressa, as mudanças constantes por parte da federação internacional. Você estuda, mas sempre vai ter que estudar para aprimorar mais. Quando troca constantemente as regras, não é possível acompanhar tudo em tempo hábil. ” A9
}

\section{Discussão}

O objetivo do estudo foi identificar e classificar o estresse em árbitros brasileiros de GR. Para melhor compreensão da discussão dos resultados do presente estudo, faz-se necessário um maior aprofundamento acerca das particularidades da arbitragem na GR no contexto brasileiro e suas relaçóes com o surgimento do estresse.

Os resultados deste estudo indicam que as questōes de natureza social se constituem fonte de estresse para os árbitros de GR, corroborando os resultados encontrados em estudos com árbitros de outras modalidades esportivas ${ }^{14,16,17}$. Em geral, as ginastas são avaliadas quanto o nível de dificuldade de sua série (adição) e quanto às faltas técnicas e artísticas eventualmente cometidas (dedução) $)^{3,21,22}$. Para isso, os árbitros são divididos, por meio de sorteio, em subgrupos dentro da mesma banca de arbitragem, de maneira que cada subgrupo fica responsável pela avaliaçáo conjunta de critérios específicos ${ }^{21}$. Corroborando com os resultados aqui encontrados o trabalho de Duda et al. ${ }^{17}$, o item "conflitos e desacordos entre juízes" foi uma fonte de estresse frequente nas respostas dos árbitros de ginástica artística, que tem uma estrutura de banca 
de arbitragem similar à GR. Fatores estressantes semelhantes a esse, como a falta de responsabilidade e/ou cooperação por parte dos colegas e as dificuldades em atuar conjuntamente com outros árbitros também estão presentes na atividade de árbitros de modalidades coletivas ${ }^{15,16}$.

Dentre os possíveis equívocos presentes na arbitragem de GR se destacam aqueles provenientes das discrepâncias dos julgamentos de um mesmo exercício, de uma mesma atleta, por diferentes árbitros, normalmente ocasionadas pelas discordâncias de argumentos ${ }^{18}$. Esse é um fator de extrema relevância, pois há necessidade de diálogo para se chegar a uma nota comum ao final do julgamento de determinados critérios ${ }^{21}$. Ademais, a discrepância de critérios entre os árbitros parece ser maior nas ginastas do tercil intermediário do ranking ${ }^{21}$. Frequentemente os julgamentos divergentes ocasionam estresse e insatisfaçóes não só entre os árbitros, mas também entre árbitros e treinadores, atletas e espectadores ${ }^{11,15,22,23}$. Esses conflitos, oriundos de desacordos no julgamento, potencializam o surgimento de fatores estressantes sociais entre todos os envolvidos neste contexto e, consequentemente, afetam as notas das ginastas ${ }^{3,30}$. Uma possível alternativa para minimizar as divergências de percepçôes quanto ao julgamento seria a utilizaçáo, mais frequente e mais rápida, de recurso de vídeo durante o andamento da competição. Entretanto, essa é uma prática que só se aplica mediante recurso formal na GR e, mesmo em outras modalidades esportivas ainda há muita controvérsia quanto aos reais benefícios da utilização da tecnologia nesse contexto ${ }^{31}$.

Parte dos fatores que geram o estresse social nos árbitros de GR estão relacionados à organização dos campeonatos em que estes profissionais atuam ${ }^{3,18}$. Da mesma forma, Duda et al. ${ }^{17}$ apontam que os problemas organizacionais que os árbitros de ginástica artística vivenciam nos eventos constituem uma fonte de estresse para os mesmos. Outras evidências deste tipo de problema estão relacionadas ao mau posicionamento dos árbitros com relação aos atletas durante seus exercícios ${ }^{19}$. Além de ser um fator de estresse ${ }^{5,10}$ o fato de estar em uma posição desfavorável para o julgamento das apresentaçóes influencia diretamente o desempenho dos árbitros ${ }^{19}$. Outros fatores como atrasos, mudanças de programação ${ }^{17}$ e som alto durante a competição também são estressores de ordem social, ligados à logística dos eventos em que os árbitros de ginástica atuam ${ }^{3,18}$.
Outro grupo de fatores estressantes para os árbitros de GR relaciona-se às dificuldades de conciliar as demandas da vida social com a carreira na arbitragem. Os árbitros de ginástica não atuam exclusivamente nessa função, pois o pró-labore desses profissionais é pago como diárias por evento. Atualmente, no Brasil, esse valor varia de acordo com o brevet do árbitro (estadual, nacional ou internacional), que pode ir de 80 a 120 reais por dia de trabalho. Logo, os árbitros devem administrar as demandas da carreira de arbitragem com suas profissóes, famílias, estudos, etc. Há evidências que mostram que as fontes de estresse, o nível de reconhecimento e remuneração deficitária são razóes para que árbitros abandonem a atividade.

No caso específico da GR, os árbitros são pouco exigidos do ponto de vista físico, já que estes profissionais atuam assentados e não dependem diretamente do seu condicionamento físico ${ }^{3,21}$. O desgaste físico destes árbitros está relacionado a diferentes variáveis, como por exemplo, o fato de manter-se assentado por muitas horas pode provocar dores lombares e desconforto nas pernas; a elevada temperatura dos ginásios de competição interfere no processo de hidratação e, consequentemente, nas demandas fisiológicas ${ }^{3}$. Porém, também existem semelhanças de fatores estressantes de ordem biológica que ocorrem em árbitros de qualquer modalidade esportiva, como por exemplo, arbitrar doente, com indisposiçóes ou dores de cabeça e lesôes no corpo?. Ainda na dimensão biológica, outro fator de estresse para estes profissionais é o fato de que algumas competiçôes são de longa duração e com poucos intervalos de descanso ${ }^{18}$. $\mathrm{O}$ cansaço proveniente da atuação por mais de seis horas e/ou da atuação em competições com muitas ginastas é um fator de estresse para os árbitros de $\mathrm{GR}^{18}$ e ginástica artística ${ }^{17}$, além de prejudicar a qualidade e assertividade das decisóes tomadas por estes profissionais ${ }^{3,21}$.

Os intervalos de descanso dos árbitros são estabelecidos de acordo com a programação das competiçôes em que atuam. Em competiçôes longas, esses intervalos são mais curtos e menos frequentes. Essa situação pode desencadear uma série de demandas fisiológicas sofridas pelos árbitros durante sua atuação como fome, sede e vontade de ir ao banheiro ${ }^{18}$. Duda et al. ${ }^{17}$ afirmam que os árbitros de ginástica consideram essas demandas acima citadas como fatores de estresse em suas atuaçôes.

Vale considerar também que a ginástica é caracterizada pela presença de um componente 
artístico $^{20}$, que torna a avaliação e interpretação dos árbitros subjetiva ${ }^{21,22,32}$, o que potencializa os fatores estressantes de origem psicológica. Esse é um dos principais fatores de estresse para os árbitros de GR, pois aumenta a sua responsabilidade enquanto avaliador do desempenho das ginastas ${ }^{22}$ possibilitando muitas vezes um maior número de erros e desacordos das notas e no julgamento ${ }^{21,22}$. Além disso, essas variaçóes nas notas, oriundas de diferentes processos de percepçáo subjetiva no julgamento dos árbitros ${ }^{30}$, podem desencadear uma série de outros fatores estressantes para os árbitros ${ }^{3,32}$.

O medo de tomar decisões erradas e as preocupaçóes com o nível do seu desempenho são fatores de estresse comuns a árbitros de diferentes esportes $^{10,31}$. Essa situação não é diferente com os árbitros de GR, já que qualquer décimo de ponto que atribuem e/ou deduzem de forma equivocada pode mudar todo resultado de uma competição, e por isso desencadear um estado de estresse ${ }^{21,32}$. Conforme observado no presente estudo, essa questão é intensificada quanto se trata de eventos importantes como seletivas nacionais. Isso ocorre porque os árbitros têm consciência que o papel deles é julgar o momento, o que foi apresentado pela atleta ali e não o processo evolutivo a médio/ longo prazo, títulos, currículo, etc. Entretanto, já existem discussóes quanto a real eficácia da seleção de atletas neste tipo de evento ${ }^{12}$, tendo em vista que as atletas mais bem preparadas podem não compor o grupo selecionado por pequenas eventualidades, e isso gera estresse na atuação do árbitro.

Após a apresentação da ginasta, o árbitro tem um tempo inferior a um minuto para atribuir a sua nota e enviá-la ao árbitro superior, que por sua vez, também tem um espaço curto de tempo para analisar as notas recebidas e decidir sobre a nota final do exercício julgado. Essa pressão de tempo que o árbitro sofre para perceber, avaliar e registrar um exercício constitui-se mais um problema no julgamento da $\mathrm{GR}^{18} \mathrm{e}$, consequentemente, mais um fator de estresse psicológico.

Uma característica particular da GR, que também acontece na ginástica artística, são as frequentes mudanças que acontecem nas regras destas modalidades ${ }^{20}$. Essa situação é um fator causador de estresse para árbitros de ginástica já que, constantemente, esses profissionais têm que adequar seus critérios e formas de avaliar às novas regras ${ }^{17}$. Ao identificar os fatores de estresse em árbitros norte-americanos de ginástica artística, DuDA et al. ${ }^{17}$ encontraram que um dos fatores de estresse são as dificuldades que eles apontam em acompanhar as constantes mudanças das regras.

As poucas evidências científicas relacionadas ao estudo do estresse em árbitros de GR foi apenas um dos fatores limitantes deste estudo. Logo, cabe ressaltar que a utilização de apenas uma técnica, sem uma triangulação de dados, também constituiu uma limitaçáo, assim como o fato de que, apesar dos entrevistados atuarem em eventos internacionais, os achados deste estudo são referentes apenas à realidade de árbitros brasileiros de GR, pois não foram entrevistados árbitros de outras nacionalidades considerados também de nível internacional.

Pode-se observar, a partir dos resultados do presente estudo, que as variáveis de estresse que estão envolvidas na atividade laboral dos árbitros brasileiros de GR, mapeadas a partir de três grandes blocos (social, biológico e psicológico), podem ser subcategorizadas a partir de fatores específicos que se interagem e se relacionam no aparecimento do estresse nestes profissionais.

Entende-se que a principal contribuição deste estudo consistiu na identificação, classificação e discussão dos fatores de estresse específico da atividade laboral dos árbitros brasileiros de GR. Além disso, constitui-se como um importante passo no sentido de mapear o estresse, enquanto constructo psicológico que influencia a atuação dos árbitros esportivos. Sabendo-se mais a respeito dos fatores que interferem na arbitragem, medidas futuras podem ser tomadas para que os árbitros tenham melhores desempenhos e, consequentemente, contribuam para o crescimento da modalidade como um todo. 


\section{Abstract}

\section{Stress in judges of Rhythmic Gymnastics}

The aim of this study was to identify and classify stress in rhythmic gymnastics judges. Ten Brazilian judges of rhythmic gymnastics, of international level, were interviewed, with the average age of 37,6 $\pm 6,6$ years old. An interview transcription was made and later, some qualitative analysis was taken place, through the use of Meaning Units (MUs). These MUs were classified in three categories: social, biological and psychological stress. Besides the difficulty in conciliating social life and professional life, the relationship with other judges, technical committee and audience are important sources of social stress to the interviewees. Relating to biological stress, judges complained about the long duration of competitions. They often present some sort of physical discomfort during their labor action. The psychological stress, to which they are under influence, has relation to the emotional distress of giving scores to the performance of athletes, in addition to the high level of the competitions they work in and the need to interpret the code of points. It is possible to conclude that the stress of Brazilian judges of rhythmic, from specific factors, they interact and relate between themselves to create stress in these professionals.

KEYWoRds: Labor activity; Physical Education and Training; Sports; Qualitative research.

\section{Referências}

1. Costa VT, Ferreira RM, Penna EM, et al. Análise estresse psíquico em árbitros de futebol. Rev Bras Psicol Esporte. 2010;3:2-16.

2. Brandão R, Serpa S, Krebs R, et al. El significado de arbitrar: percepción de jueces de fútbol profesional. Rev Psicol Deport. 2011;20:275-286.

3. Debien PB, Noce F, Debien JBP, et al. O estresse na arbitragem de ginástica rítmica: uma revisão sistemática. Rev Educ Física/UEM. 2014;25:489-500.

4. Hancock DJ, Dawson DJ, Auger D. Why ref? Understanding sport officials' motivations to begin, continue, and quit. Mov Sport Sci. 2015;87:31-39.

5. Anshel MH, Kang M, Jubenville C. Sources of acute sport stress scale for sports officials: Rasch calibration. Psychol Sport Exerc. 2013;14:362-370.

6. Samulski DM, Noce F, Chagas MH. Estresse. In: Psicologia do Esporte: conceitos e novas perspectivas. Barueri: Manole, 2009, p. 231-264.

7. Fletcher D, Scott M. Psychological stress in sports coaches: a review of concepts, research, and practice. J Sports Sci. 2010;28:127-37.

8. Mazzola JJ, Schonfeld IS, Spector PE. What qualitative research has taught us about occupational stress. Stress Heal. 2011;27:93-110.

9. Friman M, Nyberg C, Norlander T. Threats and aggression directed at soccer referees: an empirical phenomenological psychological study. Qual Rep. 2004;9:652-672.

10. Mirjamali E, Ramzaninezhad R, Rahmaninia F, et al. A study of sources of stress in international and national referees of soccer, volleyball, basketball and handball in Iran. World J Sport Sci. 2012;6:347-354.

11. Balch MJ, Scott D. Contrary to popular belief, refs are people too! Personality and perceptions of officials. J Sport Behav. 2007;30:3-20.

12. Cuskelly G, Hoye R. Sports officials' intention to continue. Sport Manag Rev. 2013;16(4):451-464.

13. Guillén F, Feltz DL. A conceptual model of referee efficacy. Front Physiol. 2011;2:25.

14. Voight M. Sources of stress and coping strategies of US soccer officials. Stress Heal. 2009;25:91-101.

15. Tsorbatzoudis H, Kaissidis-Rodafinos A, Grouios G, et al. Sources of stress among greek team handball referees: construction and validation of the handball officials' sources of stress survey. Percept Mot Skills. 2005;100:821-830.

16. Dorsch KD, Paskevich DM. Stressful experiences among six certification levels of ice hockey officials. Psychol Sport Exerc. 2007;8:585-593. 
17. Duda JL, Borysowicz MAB, St Germaine K. Women's artistic gymnastics judges' sources of stress. Technique. 1996;16: 1-5.

18. Perederij V. The problem of the quality of judging in rhythmic gymnastics. Pedagog Psychol Medical-biological Probl Phys Train Sport. 2013;63:43-46.

19. Dallas G, Mavidis A, Chairopoulou C. Influence of angle of view on judges' evaluations of inverted cross in men's rings. Percept Mot Skills. 2011;112:109-121.

20. Oliveira MS, Bortoleto MAC. O código de pontuação da ginástica artística masculina ao longo dos tempos. Rev Educ Física UEM. 2009;20:97-107.

21. Leandro C, Ávila-Carvalho L, Sierra-Palmeiro E, et al. Judging in Rhythmic Gymnastics at different levels of performance. J Hum Kinet. 2017;60:159-165.

22. Flessas K, Mylonas D, Panagiotaropoulou G, et al. Judging the judges' performance in rhythmic gymnastics. Med Sci Sport Exerc. 2015;47:640-648.

23. Ferreirinha J, Carvalho J. Tendências e desvios no ajuizamento em ginástica. Rev ENGym. 2012;1:2-3.

24. Engel R, Schutt R. Survey research. In: Grinnell R, Unrau, Y, organizadores. Social work research and evaluation foundations of evidence-base practice. Oxford: Oxford University Press; 2011. p. 326-364.

25. Patton MQ. Qualitative research \& evaluation methods: integrating theory and practice. 4 ed. Thousand Oaks: Sage, 2015.

26. Munroe-Chandler KJ. A discussion on qualitative research in physical activity. Athletic Insight. 2005;7(1):67-81.

27. Smith B, Caddick N. Qualitative methods in sport: a concise overview for guiding social scientific sport research. Asia Pacific J Sport Social Sci. 2012; (1):60-73.

28 Taylor S, Bogdan R, DeVault M. Introduction to qualitative research methods: a guidebook and resource. 4 ed. Hoboken: Wiley; 2015.

29. Côté J, Ericsson KA, Law M. Tracing the development of athletes using retrospective interview methods: a proposed interview and validation procedure for reported information. J Appl Sport Psychol. 2005;17(1):1-19.

30. Plessner H, Haar T. Sports performance judgments from a social cognitive perspective. Psychol Sport Exerc. 2006;7: 555-575.

31. Dyer B. The controversy of sports technology: a systematic review. Springerplus. 2015;4:524.

32. Plessner H. Expectation biases in gymnastic judging. J Sport Exerc Psychol. 1999;21:131-144.

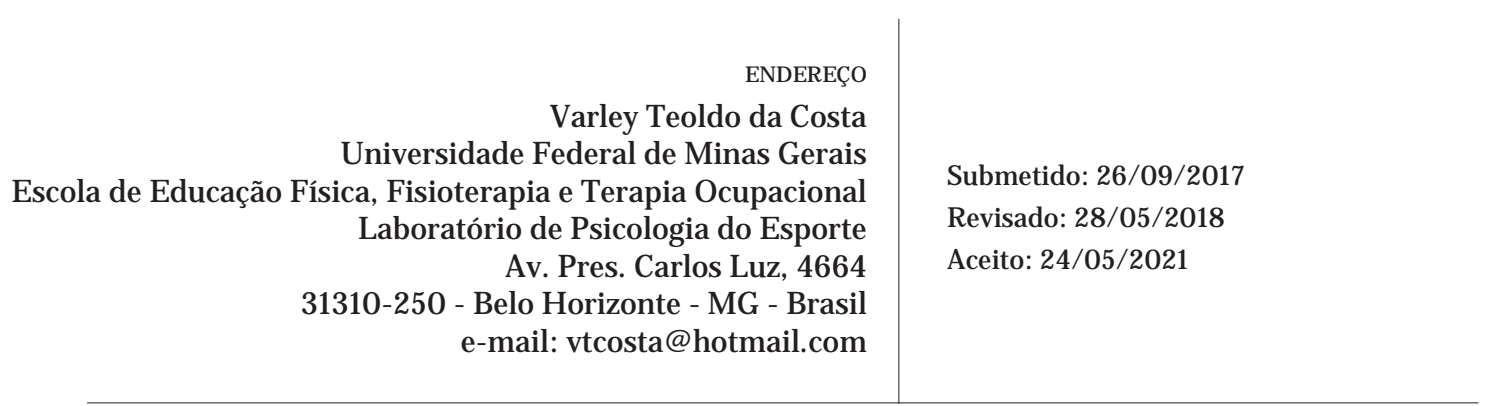

